\title{
Influence of renal function on clinico-pathological features of primary hyperparathyroidism
}

Hiroyuki Yamashita, Shiro Noguchi, Shinya Uchino, Shin Watanabe, Tsukasa Murakami, Takahiro Ogawa, Toshihiro Masatsugu, Yuji Takamatsu, Eiji Miyatake and Hiroto Yamashita

Noguchi Thyroid Clinic and Hospital Foundation, 6-33 Noguchi-Nakamachi, Beppu Oita 874-0932, Japan

(Correspondence should be addressed to H Yamashita; Email: yama@noguchi-med.or.jp)

\begin{abstract}
Objective: Disturbed renal function may play an important role in the clinico-pathological presentation of primary hyperparathyroidism (pHPT). We studied the influence of renal function on the clinicopathological characteristics of 141 patients (123 women and 18 men) with surgically proven pHPT. Methods: The 141 patients were assigned to one of two groups based on creatinine clearance $\left(\mathrm{C}_{\mathrm{cr}}\right)$ level: a renal insufficiency group $(n=37)$ in which $C_{\mathrm{cr}}$ of patients was $<70 \mathrm{ml} / \mathrm{min}$ and a normal renal function group $(n=104)$ in which $\mathrm{C}_{\mathrm{cr}}$ was $\geq 70 \mathrm{ml} / \mathrm{min}$. Clinical presentation and biochemical indices were evaluated and compared between the two groups.

Results: Age, and frequency of hypertension and of diabetes mellitus were significantly $(P<0.001$, $P<0.05$ and $P<0.05$ respectively) higher in the renal insufficiency group than in the normal renal function group. Serum levels of calcium, intact parathyroid hormone and bone Gla protein were significantly $(P<0.05)$ higher and the excised parathyroid weighed significantly more $(P<0.05)$ in the renal insufficiency group than in the normal renal function group; however, serum 1,25-dihydroxyvitamin $\mathrm{D}\left(1,25(\mathrm{OH})_{2} \mathrm{D}\right)$ and $24 \mathrm{~h}$ urinary calcium excretion were significantly $(P<0.001$ and $P<0.05$ respectively) lower in the former than in the latter group. There was a significant inverse correlation between $C_{\mathrm{cr}}$ level and serum calcium $(r=0.315, P<0.001)$ and a significant positive correlation between $\mathrm{C}_{\mathrm{cr}}$ level, 1,25(OH) $2 \mathrm{D}(r=0.315, \mathrm{P}<0.001)$, and $24 \mathrm{~h}$ calcium excretion $(r=0.458, P<0.0001)$.

Conclusions: Clinico-pathological features of pHPT were notably influenced by even moderate renal insufficiency. Urinary calcium excretion decreased according to the decrease in glomerular filtration rate. Therefore, endocrinologists need to appraise urinary calcium excretion and renal function of pHPT patients when considering surgery or in discriminating familial hypocalciuric hypercalcemia.
\end{abstract}

European Journal of Endocrinology 148 597-602

\section{Introduction}

Primary hyperparathyroidism (pHPT) differs clinically from secondary HPT, which is a well-established complication of chronic renal failure. Parathyroid hormone (PTH) acts on the kidney to increase the production of 1,25-dihydroxyvitamin D $\left(1,25(\mathrm{OH})_{2} \mathrm{D}\right)(1)$, which increases intestinal absorption and renal reabsorption of calcium (2) and also aids calcemic action of PTH to the bone (3). In pHPT, $1,25(\mathrm{OH})_{2} \mathrm{D}$ is increased by hypersecretion of PTH; conversely, lack of $1,25(\mathrm{OH})_{2} \mathrm{D}$ can be a major factor in maintaining PTH hypersecretion in secondary HPT.

Prolonged hypercalcemia impairs renal function, and a reduced glomerular filtration rate (GFR) is a common finding in advanced-stage pHPT $(4,5)$. There have been many studies on the metabolism of calcium, vitamin D and bone in both pHPT and secondary HPT; however, there are few reports of the clinico-pathological effects of renal insufficiency in patients with pHPT. We have encountered several surgically proven pHPT patients in whom $24 \mathrm{~h}$ urinary calcium excretion was extremely low, probably due to renal insufficiency. Low urinary calcium excretion is the most significant discriminating factor between pHPT and familial hypocalciuric hypercalcemia (FHH). FHH is a dominantly inherited disorder of divalent cation metabolism, and there are clinical and biochemical overlaps with pHPT. However, surgery is not indicated for $\mathrm{FHH}$.

We hypothesized that clinico-pathological features of pHPT are modified by impaired renal function, and we reviewed the clinico-pathological features of patients with surgically proven pHPT, giving special attention to renal function. This is important for the diagnosis and treatment of pHPT because impaired renal function is a well-known complication of pHPT $(4,5)$. 


\section{Patients and methods}

\section{Patient selection}

One hundred and fifty-five patients with pHPT underwent surgery at our hospital between September 1998 and February 2002. There were none with renal failure. Of the 155 patients, we excluded three with multiple endocrine neoplasia type 1 , one with parathyroid cancer and parathyroid apoplexy, one who was wheelchair-bound and three with persistent HPT after surgery. Creatinine clearance $\left(\mathrm{C}_{\mathrm{cr}}\right)$ data were available for 141 of the remaining 146 patients, and these 141 were the study group. No patient had been taking medications that are known to interfere with calcium and vitamin D metabolism for at least 2 weeks before hospital admission. Of the 141 patients, $47(33 \%)$ visited or were referred to us because of a thyroid nodule, and pHPT was diagnosed by calcium screening and a subsequent work-up including measurements of serum PTH and urinary calcium excretion. Medical histories included thyroidectomy for papillary thyroid cancer $(n=7)$, benign thyroid tumor $(n=6)$, and Graves' disease $(n=2)$. Two patients were referred for persistent hypercalcemia after parathyroidectomy.

\section{Laboratory tests}

Blood and urine samples were collected after overnight fasting. Serum levels of alkaline phosphatase, total calcium, albumin and inorganic phosphate were determined by routine automated procedures. Ionized calcium and magnesium concentrations were determined with an electrolyte analyzer (NOVA Biomedical, Waltham, MA, USA). The corrected calcium level was calculated as: (calcium concentration $(\mathrm{mg} / \mathrm{dl}))+(4$-albumin $(\mathrm{g} / \mathrm{dl}))$. Serum intact PTH (iPTH) was measured by a two-site immunochemiluminometric assay. Serum 25-hydroxyvitamin D (250HD) levels were measured by a competitive protein-binding assay with HPLC purification and had intra- and interassay coefficients of variation (CVs) of 5.8 and $12.6 \%$ respectively (6). Serum $1,25(\mathrm{OH})_{2} \mathrm{D}$ levels were measured by a receptor-binding assay with bovine mammary gland receptor and had intra- and interassay CVs of 8.1 and $8.3 \%$ respectively (7). Serum bone Gla protein (BGP) was measured with a Mitsubishi Yuka BGP IRMA kit (Tokyo, Japan) that uses a mouse monoclonal antibody to human BGP. Urinary calcium excretion was assessed by atomic absorption spectrometry, and $\mathrm{C}_{\mathrm{cr}}$ was calculated on the basis of $\mathrm{ml} / \mathrm{min}$ per $1.48 \mathrm{~m}^{2}$ of body surface area by measuring three consecutive urine collections at $24 \mathrm{~h}$ intervals while the patient was taking approximately $400 \mathrm{mg}$ calcium/day. The normal value was assumed to be $\geq 70 \mathrm{ml} / \mathrm{min}(8)$. To assess bone resorption, an ELISA was used to measure urinary excretion of collagen type 1 cross-linked N-telopeptides (NTx) (Osteomark; Ostex International, Seattle, WA, USA), and the results were corrected according to urinary creatinine concentrations assessed by a standard colorimetric method.

\section{Statistical analysis}

Mean \pm S.D. data are shown unless otherwise indicated. ANOVA was used to assess differences between the groups. Multivariate analyses were done with a logistic model. Categorical data were analyzed with Pearson's $\chi^{2}$ test. Correlation was determined by calculating Pearson's correlation coefficient. Statistical analyses were performed with SAS-JMP version 4.0.2 software (SAS Institute Inc., Cary, NC, USA). A two-sided $P<0.05$ was considered significant.

\section{Results}

Patient's clinical and biochemical data are summarized in Table 1 . Of the 123 women, 96 were postmenopausal, but none were under estrogen therapy. There was a history of nephrolithiasis in 35 patients, bone fracture in 15 and peptic ulcer in 13. Four patients complained of severe fatigue. The remaining 84 patients $(60 \%)$ had asymptomatic pHPT. The mean serum calcium level was $2.70 \pm 0.21 \mathrm{mmol} / \mathrm{l}$. At least one enlarged parathyroid gland was resected in each patient; the mean weight of the resected parathyroid was $857 \pm 1962 \mathrm{mg}$ (range 66-21 $834 \mathrm{mg}$ ). A single gland was diseased in 127 cases, and multiglandular disease was present in 14 cases.

The 141 patients were assigned to one of two groups based on $\mathrm{C}_{\mathrm{cr}}$ level: a renal insufficiency group $(n=37)$

Table 1 Preoperative clinical and biochemical data for pHPT patients. Mean \pm S.D. data are shown.

\begin{tabular}{lcc}
\hline & Value & Reference range \\
\hline Age (years) & $58 \pm 13$ & - \\
Sex (F/M) & $123 / 18$ & - \\
Serum albumin (g/l) & $3.62 \pm 0.29$ & $3.5-4.8$ \\
Serum calcium (mmol/l) & $2.70 \pm 0.21$ & $2.20-2.54$ \\
lonized calcium (mmol/l) & $1.48 \pm 0.12$ & $1.08-1.26$ \\
Serum corrected calcium (mmol/l) & $2.80 \pm 0.18$ & $2.20-2.54$ \\
Serum phosphate (mmol/dl) & $0.98 \pm 0.16$ & $0.81-1.45$ \\
Serum creatinine $(\mu \mathrm{mol} / \mathrm{l})$ & $62 \pm 17$ & $44-100$ \\
Serum blood urea nitrogen & $4.9 \pm 1.4$ & $3.2-6.8$ \\
$\quad(\mathrm{mmol} / \mathrm{l})$ & $18.4 \pm 16.3$ & $2.5-13$ \\
Serum BGP (ng/ml) & $136 \pm 95$ & $43-155$ \\
Serum alkaline phosphatase (IU/l) & $19 \pm 30$ & $1.1-7.4$ \\
iPTH (pmol/l) & $35.8 \pm 14.9$ & $25-137$ \\
25OHD (nmol/l) & $170 \pm 65$ & $48-144$ \\
$1,25(\mathrm{OH})_{2} \mathrm{D}(\mathrm{pmol} / \mathrm{l})$ & $167 \pm 353$ & $14-100$ \\
Urinary NTx (nmol BCE/mmol & & \\
$\quad$ creatinine) & $857 \pm 1962$ & - \\
Parathyroid gland weight $(\mathrm{mg})^{\mathrm{a}}$ & & \\
\hline
\end{tabular}

${ }^{\mathrm{a}}$ In the case of multiglandular disease, weight is calculated as the sum of resected parathyroid glands. $\mathrm{BCE}$, bone collagen equivalents. 
in which $\mathrm{C}_{\mathrm{cr}}$ of patients was $<70 \mathrm{ml} / \mathrm{min}$ and a normal renal function group $(n=104)$ in which $C_{c r}$ was $\geq 70 \mathrm{ml} / \mathrm{min}(8)$. Age and the frequency of hypertension, diabetes mellitus and multiglandular disease were significantly higher in the renal insufficiency group than in the normal renal function group (Table 2). Serum levels of calcium and iPTH, parathyroid gland weight and BGP were significantly higher in the renal insufficiency group than in the normal renal function group; however, $24 \mathrm{~h}$ urinary calcium and phosphate were significantly lower in the renal insufficiency group than in the normal function group (Tables 3 and 4). According to multivariate analysis of the clinical and biochemical factors, ageand serum-corrected calcium levels were significant independent factors predictive of renal insufficiency (Table 5).

Correlations between $\mathrm{C}_{\mathrm{cr}}$ and $1,25(\mathrm{OH})_{2} \mathrm{D}$ and $24 \mathrm{~h}$ calcium excretion are shown in Fig. 1. In both groups, there was a significant correlation $(P<0.005)$ between $C_{c r}$ and $24 \mathrm{~h}$ calcium excretion; however, a significant correlation between $\mathrm{C}_{\mathrm{cr}}$ and $1,25(\mathrm{OH})_{2} \mathrm{D}$ was found only in the renal insufficiency group $(P<0.01)$.

\section{Discussion}

Our study documents several clinico-pathological features of pHPT modified by renal insufficiency.

Table 2 Clinical data of pHPT patients per group. Mean \pm S.D. data are shown.

\begin{tabular}{|c|c|c|c|}
\hline & Renal insufficiency group $(n=37)$ & Normal renal function group $(n=104)$ & $\boldsymbol{P}$ \\
\hline Age (years) & $64 \pm 11$ & $55 \pm 12$ & $<0.001^{\mathrm{a}}$ \\
\hline $\operatorname{Sex}(F / M)$ & $30 / 7$ & $93 / 11$ & 0.192 \\
\hline Urinary stone disease (\%) & 27 (10 patients) & 24 (25 patients) & 0.718 \\
\hline Bone disease $(\%)$ & 24 (9 patients) & 20 (21 patients) & 0.598 \\
\hline Hypertension (\%) & 46 (17 patients) & 19 (20 patients) & $<0.005$ \\
\hline Diabetes mellitus (\%) & 19 (7 patients) & 7 (7 patients) & $<0.005$ \\
\hline Parathyroid gland weight $(\mathrm{mg})^{\mathrm{b}}$ & $1450 \pm 3586$ & $646 \pm 754$ & $<0.05$ \\
\hline Single gland disease (\%) & 81 (30 patients) & 93 (97 patients) & $<0.05$ \\
\hline Multiglandular disease (\%) & 19 (7 patients) & 7 (7 patients) & $<0.05$ \\
\hline
\end{tabular}

a Statistical significance of between group difference determined by Student's $t$-test or Pearson's $\chi^{2}$ test.

${ }^{\mathrm{b}}$ In case of multiglandular disease, weight is calculated as the sum of resected parathyroid glands.

Table 3 Biochemical data of pHPT patients per group. Mean \pm S.D. data are shown.

\begin{tabular}{|c|c|c|c|}
\hline & Renal insufficiency group $(n=37)$ & Normal renal function group $(n=104)$ & $\boldsymbol{P}$ \\
\hline Serum albumin $(g / l)$ & $3.58 \pm 0.35$ & $3.63 \pm 0.27$ & $0.390^{\mathrm{a}}$ \\
\hline Serum calcium (mmol/l) & $2.78 \pm 0.26$ & $2.68 \pm 0.18$ & $<0.05$ \\
\hline Ionized calcium (mmol/l) & $1.53 \pm 0.13$ & $1.46 \pm 0.11$ & $<0.005$ \\
\hline Serum corrected calcium (mmol/l) & $2.88 \pm 0.23$ & $2.77 \pm 0.15$ & $<0.005$ \\
\hline Serum phosphate $(\mathrm{mmol} / \mathrm{l})$ & $0.95 \pm 0.16$ & $1.00 \pm 0.16$ & 0.116 \\
\hline Serum creatinine $(\mu \mathrm{mol} / \mathrm{l})$ & $75 \pm 24$ & $57 \pm 11$ & $<0.001$ \\
\hline Serum blood urea nitrogen $(\mathrm{mmol} / \mathrm{l})$ & $5.7 \pm 1.6$ & $4.5 \pm 1.1$ & $<0.001$ \\
\hline
\end{tabular}

${ }^{\text {a }}$ Statistical significance of between group difference determined by Student's $t$-test.

Table 4 Clinical and biochemical data of pHPT patients per group. Mean \pm S.D. data are shown.

\begin{tabular}{|c|c|c|c|}
\hline & Renal insufficiency group $(n=37)$ & Normal renal function group $(n=104)$ & $\boldsymbol{P}$ \\
\hline Serum BGP (ng/ml) & $27.1 \pm 28.5$ & $15.8 \pm 8.2$ & $<0.005^{\mathrm{a}}$ \\
\hline Serum alkaline phosphatase (IU/I) & $158 \pm 160$ & $129 \pm 55$ & 0.104 \\
\hline $\mathrm{iPTH}(\mathrm{pmol} / \mathrm{l})$ & $28 \pm 56$ & $15 \pm 9$ & $<0.05$ \\
\hline 25OHD (nmol/l) & $37.7 \pm 17.1$ & $35.7 \pm 13.9$ & 0.498 \\
\hline $1,25(\mathrm{OH})_{2} \mathrm{D}(\mathrm{pmol} / \mathrm{l})$ & $145 \pm 65$ & $179 \pm 63$ & $<0.01$ \\
\hline Urinary NTx (nmol BCE/mmol creatinine) & $223 \pm 45$ & $149 \pm 315$ & 0.306 \\
\hline $24 \mathrm{~h}$ urinary calcium excretion $(\mathrm{mmol})$ & $5.07 \pm 2.36$ & $6.83 \pm 2.10$ & $<0.001$ \\
\hline Calcium excretion rate $(\%)^{\mathrm{b}}$ & $2.14 \pm 0.70$ & $1.77 \pm 0.51$ & $<0.005$ \\
\hline $24 \mathrm{~h}$ urinary phosphate excretion (mmol) & $16.5 \pm 4.6$ & $20.9 \pm 4.7$ & $<0.001$ \\
\hline TRP (\%) & $81 \pm 5$ & $78 \pm 7$ & $<0.05$ \\
\hline
\end{tabular}

a Statistical significance of between group difference determined by Student's $t$-test.

${ }^{\mathrm{b}}$ Calcium excretion rate was calculated as: (urinary calcium $(\mathrm{mg} / \mathrm{dl}) \times$ serum creatinine $\left.(\mathrm{mg} / \mathrm{dl})\right) /($ urinary creatine $(\mathrm{mg} / \mathrm{dl}) \times$ serum calcium $(\mathrm{mg} / \mathrm{dl})) \times 100$. TRP, tubular resorption of phosphate. 
Table 5 Multivariate analysis of clinical and biochemical factors for renal insufficiency in patients with pHPT.

\begin{tabular}{lc}
\hline Clinical factor & $\boldsymbol{P}$ \\
\hline Age & 0.004 \\
Frequency of hypertension & 0.180 \\
Frequency of diabetes mellitus & 0.328 \\
Frequency of multiglandular disease & 0.085 \\
Corrected calcium & 0.013 \\
Parathyroid weight & 0.297 \\
\hline
\end{tabular}
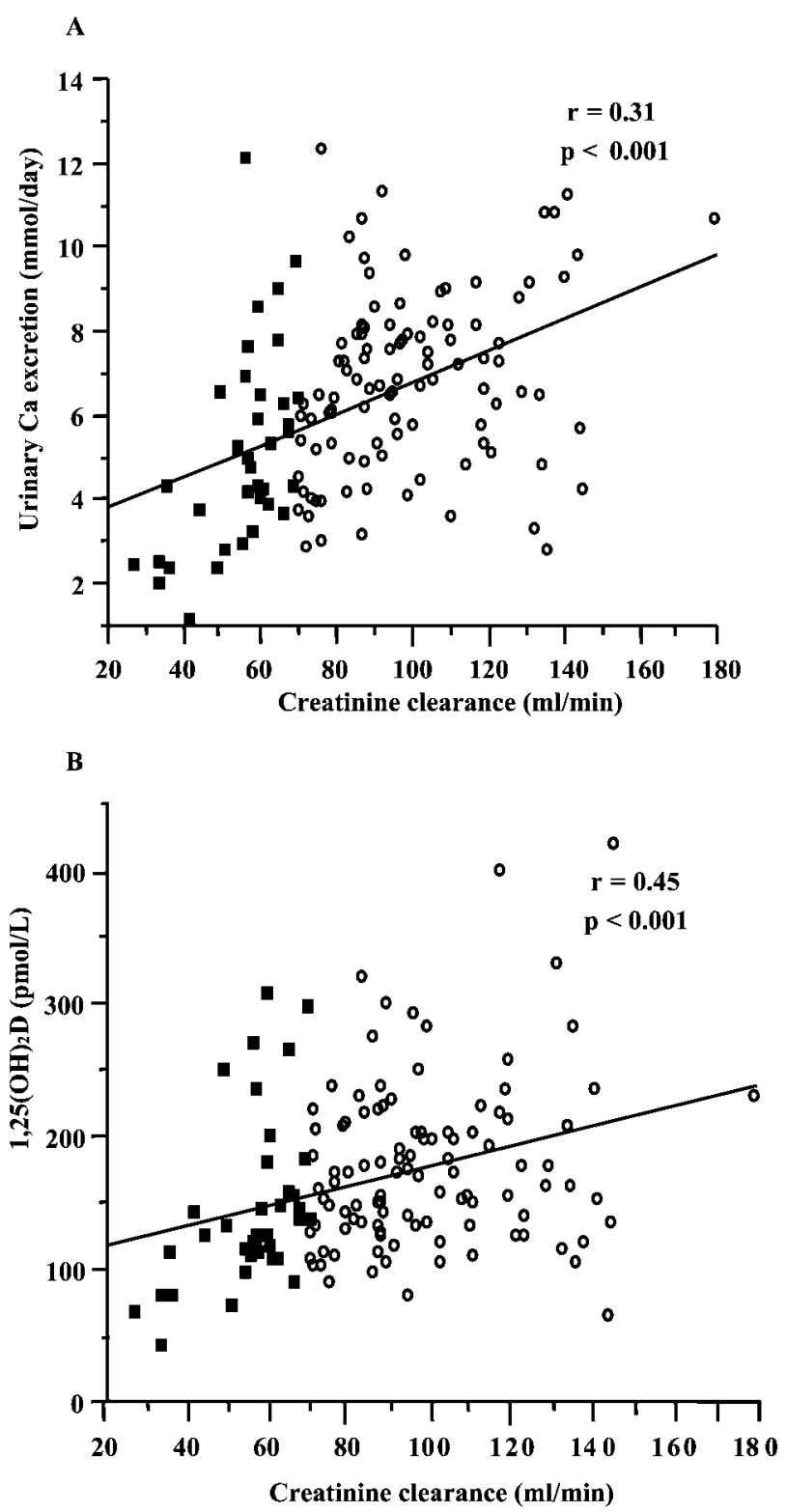

Figure 1 (A) Correlation between $\mathrm{C}_{\mathrm{cr}}$ and $24 \mathrm{~h}$ urinary calcium excretion. $\mathbf{\square}$, Renal insufficiency subjects; $\bigcirc$, normal renal function subjects. (B) Correlation between $\mathrm{C}_{\mathrm{cr}}$ and serum $1,25(\mathrm{OH})_{2} \mathrm{D}$. $\mathbf{0}$, Renal insufficiency subjects; $\bigcirc$, normal renal function subjects.
These have not been fully investigated previously, and they have important clinical implications for the diagnosis and treatment of pHPT. The degree of renal insufficiency in the present study was mild considering that the mean serum levels of creatinine and blood urea nitrogen in the renal insufficiency group were $75 \mu \mathrm{mol} / \mathrm{l}$ and $5.8 \mathrm{mmol} / \mathrm{l}$ respectively. There have been several studies documenting abnormalities in calcium, phosphorus and vitamin D metabolism in patients with renal disease. Secondary HPT is also present in moderate renal failure, and elevated blood levels of PTH have been found in patients with $\mathrm{C}_{\mathrm{cr}}<70$ $\mathrm{ml} / \mathrm{min}$ (9). Lucas et al. (10) noted a diminished mean concentration of $1,25(\mathrm{OH})_{2} \mathrm{D}$ in nephrotic patients with a GFR of $50-90 \mathrm{ml} / \mathrm{min}$ (mean 69.5). $\mathrm{A} \mathrm{C}_{\mathrm{cr}}$ of $70 \mathrm{ml} / \mathrm{min}$ was chosen to distinguish our two study groups because we hypothesized that the clinico-pathological features of pHPT may be influenced by secondary HPT.

Prolonged hypercalcemia impairs renal function, and a reduced GFR is common in advanced pHPT $(4,5)$. In our study, hypercalcemia was shown to be a significant risk factor for renal insufficiency. The incidence and severity of this renal impairment vary considerably among reports, probably due to both the heterogeneity of the patient samples studied and the different techniques used for estimating renal function. Several authors who monitored plasma creatinine levels in pHPT patients reported that renal function might remain normal despite long-standing hypercalcemia $(11,12)$.

The majority of our patients were asymptomatic; five $(3.5 \%)$ had mildly elevated serum creatinine levels, and $37(27.0 \%)$ had a $\mathrm{C}_{\mathrm{cr}}<70 \mathrm{ml} / \mathrm{min}$. The National Institutes of Health Consensus Development Conference recommends measurements of serum creatinine and $\mathrm{C}_{\mathrm{cr}}$ and advises surgery if $\mathrm{C}_{\mathrm{cr}}$ is reduced $>30 \%$ from that of age- and sex-matched controls (13). The current recommendation is unchanged, but determining $\mathrm{C}_{\mathrm{cr}}$ is recommended only in the initial assessment of patients with pHPT because its determination is variable and often unreliable in the outpatient setting. Silverberg et al. (14) reported that the renal function of patients with asymptomatic pHPT followed up for 10 years did not decrease significantly; however, we should keep in mind that renal damage, once established, persists and may even progress after parathyroid adenectomy (15).

Hypertension has been reported to be more prevalent in pHPT patients than in matched control subjects (16). The frequency of hypertension was significantly higher in our renal insufficiency group than in our normal renal function group. This is expected because the former group was older than the latter group. Further, the prevalence and severity of hypertension increase as renal function declines, even in patients with serum creatinine levels within the normal range (17). Hypertension secondary to early-stage kidney disease 
may be related to impaired sodium excretion, leading to an increase in blood volume and exchangeable body sodium (18). The frequency of diabetes mellitus was also significantly higher in the renal insufficiency group than in normal renal function group. There have been epidemiological studies showing overrepresentation of pHPT in diabetes mellitus and vice versa (19). Glucose intolerance and reduced peripheral insulin sensitivity have been shown in patients with $\mathrm{pHPT}$ (20). The high frequency of hypertension in pHPT patients together with peripheral insulin insensitivity may contribute to the increased risk of cardiovascular disease in these patients (21).

Whereas the majority of our patients had serum $1,25(\mathrm{OH})_{2} \mathrm{D}$ levels within the normal range, the mean level in the renal insufficiency group was significantly lower than that in the normal renal function group, although the former group had a higher PTH level than the latter group. PTH increases production of $1,25(\mathrm{OH})_{2} \mathrm{D}$ from $25 \mathrm{OHD}$ by stimulating renal $1-\alpha$-hydroxylase activity (1), and the serum 25OHD level did not differ between our two groups. This observation is clinically important and key to understanding progression of pHPT, which can be caused by loss of renal mass and resistance to $\mathrm{PTH}$ in patients with renal dysfunction. There are several reports that serum $1,25(\mathrm{OH})_{2} \mathrm{D}$ concentrations start to decline early in the course of renal failure $(10,22,23)$. Prolonged high circulating PTH concentrations induce downregulation of PTH peripheral receptors. Tomlinson et al. (24) showed that the urinary cAMP response to PTH is blunted in patients with HPT and that this phenomenon tends to occur in patients with high endogenous PTH concentrations. Because $1,25(\mathrm{OH})_{2} \mathrm{D}$ is required to correct skeletal resistance to the calcemic action of PTH (25), and it inhibits synthesis and secretion of PTH in vitro and in vivo $(26,27)$, reduced $1,25(\mathrm{OH})_{2} \mathrm{D}$ promotes proliferation of the parathyroid glands, resulting in a vicious cycle of HPT. We found an increased frequency of multiglandular disease in the renal insufficiency group. It can be assumed that renal insufficiency can lead to glandular hyperplasia.

Patients with pHPT have variably elevated urinary calcium levels, determined by the ratio between increased filtered load and enhanced calcium resorption. Hypocalciuria is the expected finding in normocalcemic patients with renal insufficiency, even when the GFR is minimally reduced. When the filtration rate falls to $25 \%$ or less, there is an increase in fractional calcium excretion that frequently parallels an increase in fractional sodium excretion (28). According to the NIH Consensus Development Conference statement (13), surgery is recommended if $24 \mathrm{~h}$ urinary calcium excretion is $>400 \mathrm{mg}(9.9 \mathrm{mmol})$. Our study shows that $24 \mathrm{~h}$ urinary calcium excretion is significantly lower when renal function is insufficient than when renal function is normal; therefore, endocrinologists need to evaluate urinary calcium excretion when considering renal function of patients for surgical indications or for diagnosing FHH.

Our study population differed slightly from that of other studies; there was a predominance of women and a higher prevalence of postmenopausal women than in other studies $(14,29)$. Because decreased renal function was mainly influenced by age and hypercalcemia, not by sex or menopause, and because the influence of moderate renal failure may not differ significantly between the two sexes, the main findings of this study can be applied to the general HPT population.

Clinico-pathological features of pHPT were notably influenced by even moderate renal insufficiency. Endocrinologists need to evaluate urinary calcium excretion and renal function of pHPT patients when considering surgery or discriminating between pHPT and FHH.

\section{References}

1 Garabedian M, Holick MF, DeLuca HF \& Boyle IT. Control of 25-hydroxycholecalciferol metabolism by parathyroid glands. PNAS $1972691673-1676$.

2 Coburn JW, Hartenbower DL \& Massry SG. Intestinal absorption of calcium and the effect of renal insufficiency. Kidney International 19734 96-104.

3 Massry SG, Stein R, Garty J, Arieff I, Coburn JW, Norman AW et al. Skeletal resistance to the calcemic action of parathyroid hormone in uremia: role of $1,25(\mathrm{OH})_{2} \mathrm{D} 3$. Kidney International 19769 467-474.

4 Jones DB, Jones JH, Lloyd HJ, Lucas PA, Wilkins WE \& Walker DA. Changes in blood pressure and renal function after parathyroidectomy in primary hyperparathyroidism. Postgraduate Medical Journal 198359 350-353.

5 Kristoffersson A, Backman C, Granqvist K \& Jarhult J. Pre- and postoperative evaluation of renal function with five different tests in patients with primary hyperparathyroidism. Journal of Internal Medicine 1990227 317-324.

6 Haddad JG \& Chyu KJ. Competitive protein-binding radioassay for 25-hydroxycholecalciferol. Journal of Clinical Endocrinology and Metabolism $197133992-995$.

7 Reinhardt TA, Horst RL, Orf JW \& Hollis BW. A microassay for 1,25-dihydroxyvitamin D not requiring high performance liquid chromatography: application to clinical studies. Journal of Clinical Endocrinology and Metabolism 198458 91-98.

8 Henry RJ. Creatinine clearance. In Clinical Chemistry, edn 1, ch. 24, pp 891-893. Ed. RJ Henry. New York: Harper \& Row, 1966.

9 Arnaud CD. Hyperparathyroidism and renal failure. Kidney International $1973 \mathbf{4} 89-95$.

10 Lucas PA, Brown RC, Jones C, Woodhead JS \& Coles GA. Reduced $1,25(\mathrm{OH})_{2} \mathrm{D}_{3}$ may be responsible for the development of hyperparathyroidism in early chronic renal failure. Proceedings of the European Dialysis and Transplant Association 198522 1124-1128.

11 Scholz DA \& Purnell DC. Asymptomatic primary hyperparathyroidism. 10-year prospective study. Mayo Clinic Proceedings 198156 473-478.

12 Palmer M, Jakobsson S, Akerstrom G \& Ljunghall S. Prevalence of hypercalcaemia in a health survey: a 14-year follow-up study of serum calcium values. European Journal of Clinical Investigation $19881839-46$.

13 Consensus Development Conference Panel, Diagnosis and management of asymptomatic primary hyperparathyroidism: 
Consensus Development Conference statement. Annals of Internal Medicine 1991114 593-597.

14 Silverberg SJ, Shane E, Jacobs TP, Siris E \& Bilezikian JP. A 10-year prospective study of primary hyperparathyroidism with or without parathyroid surgery. New England Journal of Medicine $19993411249-1255$.

15 Freaney R, Casey OM \& Muldowney FP. The long-term effect of parathyroidectomy on renal function. Irish Journal of Medical Science $1978147205-209$.

16 Nainby-Luxmoore JC, Langford HG, Nelson NC, Watson RL \& Barnes TY. A case-comparison study of hypertension and hyperparathyroidism. Journal of Clinical Endocrinology and Metabolism 198255 303-306.

17 Johnston PA \& Davison AM. Hypertension in adults with idiopathic glomerulonephritis and normal serum creatinine. A report from the MRC Glomerulonephritis Registry. Nephrology, Dialysis, Transplantation 19938 20-24.

18 Schiffl H, Fricke H \& Sitter T. Hypertension secondary to early-stage kidney disease: the pathogenetic role of altered cytosolic calcium $\left(\mathrm{Ca}^{2+}\right)$ homeostasis of vascular smooth muscle cells. American Journal of Kidney Diseases 199321 51-57.

19 Taylor WH \& Khaleeli AA. Prevalence of primary hyperparathyroidism in patients with diabetes mellitus. Diabetic Medicine 199714 386-389.

20 Kumar S, Olukoga AO, Gordon C, Mawer EB, France M, Hosker JP et al. Impaired glucose tolerance and insulin insensitivity in primary hyperparathyroidism. Clinical Endocrinology $1994 \mathbf{4 0}$ $47-53$.

21 Nilsson IL, Yin L, Lundgren E, Rastad J \& Ekbom A. Clinical presentation of primary hyperparathyroidism in Europe-nationwide cohort analysis on mortality from nonmalignant causes. Journal of Bone and Mineral Research 200217 N68-N74.

22 Reichel H, Deibert B, Schmidt-Gayk H \& Ritz E. Calcium metabolism in early chronic renal failure: implications for the pathogenesis of hyperparathyroidism. Nephrology, Dialysis, Transplantation $19916162-169$.

23 Pitts TO, Piraino BH, Mitro R, Chen TC, Segre GV, Greenberg G et al. Hyperparathyroidism and 1,25-dihydroxyvitamin D deficiency in mild, moderate, and severe renal failure. Journal of Clinical Endocrinology and Metabolism 198867 876-881.

24 Tomlinson S, Hendy GN, Pemberton DM \& O'Riordon JL. Reversible resistance to the renal action of parathyroid hormone in man. Clinical Science and Molecular Medicine 1976 51 59-69.

25 Massry SG \& Smogorzewski M. Parathyroid hormone, chronic renal failure and the liver. Kidney International Supplement 1997 62 S5-S7.

26 Russell J, Lettieeri D \& Sherwood LM. Suppression by 1,25-dihydroxyvitamin D3 of transcription of the pre-proparathyroid hormone gene. Endocrinology $19861192864-2866$.

27 Naveh-Many T, Friedlaender MM, Mayer H \& Silver J. Calcium regulates parathyroid hormone messenger ribonucleic acid (mRNA), but not calcitonin mRNA in vivo in the rat. Dominant role of 1,25-dihydroxyvitamin D. Endocrinology $1989 \mathbf{1 2 5}$ 275-280.

28 Popovtzer MM, Schainuck LI, Massry SG \& Kleeman CR. Divalent ion excretion in chronic kidney disease: relation to degree of renal insufficiency. Clinical Science 197038 297-307.

29 Vestergaard P, Mollerup CL, Frokjaer VG, Christiansen P, Blichert-Toft M \& Mosekilde L. Cardiovascular events before and after surgery for primary hyperparathyroidism. World Journal of Surgery 200327 216-222.

Received 14 January 2003

Accepted 2 April 2003 